\title{
Air quality estimation in Ukraine using SDG 11.6.2 indicator assessment
}

\author{
Andrii Shelestov ${ }^{1}$, Hanna Yailymova ${ }^{1,2 *}$, Bohdan Yailymov' ${ }^{2}$, Nataliia Kussul1,2
}

1 National Technical University of Ukraine “Igor Sikorsky Kyiv Polytechnic Institute”, 03056 Kyiv, Ukraine; mail@kpi.ua

2 Space Research Institute NAS Ukraine \& SSA Ukraine, 03187 Kyiv, Ukraine; inform@ikd.kiev.ua

* Correspondence: anna.yailymova@gmail.com; Tel.: +3 80939311500

\begin{abstract}
Ukraine is an associate member of the European Union and in the coming years it is expected that all the data and services already used by European Union countries will become available for Ukraine. An important program, which is the basis for building European monitoring services for Smart Cities, is the Copernicus program. The two most important services of this program are Copernicus Land Monitoring Service (CLMS) and Copernicus Atmosphere Monitoring Service (CAMS). CLMS provides important information on Land Use in Europe. In the context of Smart Cities, the most valuable one is the Urban Atlas service, which is related to local CLMS services and provides a detailed digital city plan in vector form, which is segmented into small functional areas classified by the CORIN nomenclature. The Urban Atlas is a geospatial layer with high-resolution, which is built for all European cities with a population of more than 100,000 that combines highresolution satellite data, city segmentation by blocks and functional areas, important city infrastructure, etc. This product is used as a basis for city planning and obtaining analytics on the most important indicators of city development including air quality monitoring. For Ukraine, such geospatial products are not provided under the Copernicus program. It is important to start work on its development and implementation as early as possible, so that when the first city atlas appears, Ukraine will be ready to work with it together with the European community. This requires preparing the basis for national research and training national stakeholders and users to use this product. To make this happen it's necessary to have national geospatial product, which can be used as an analogue of the city atlas.
\end{abstract}

In this article authors analyzed the existing methods of air quality assessment and assessment of the SDG indicator 11.6.2 achieving for European cities, based on which the indicator 11.6.2 for Ukraine for 5 years was evaluated for the first time. The obtained results are analyzed and the values of indicator 11.6.2 for Ukraine are compared with European countries.

Keywords: air quality monitoring, PM2.5, sustainable development goals, SDG indicator 11.6.2

\section{Introduction}

As of now there are many projects in the world that develop and use information technology to aggregate, analyze and visualize information about air pollution in cities for urban residents' timely information about possible dangers. The information sources for such monitoring systems are ground air quality measurement stations and satellite information. There are also projects that monitor air quality not only for a particular country, but for many countries or regions. One of such projects is SMURBS (SMart URBan Solutions for air quality, disasters and city growth) of Horizon-2020 ERA-Planet program, within which the National Observatory of Athens has developed a platform for monitoring the indicator 11.6.2 "Annual mean levels of fine particulate matter in cities" for 800 cities and 37 European countries [1]. Unfortunately, Ukraine is not included in the list of 
countries monitored on this platform and that is why the question in the development of a similar product for Ukraine is arises.

Ukraine has already taken some steps to create air quality monitoring systems in large cities. It is the large cities that make the biggest contribution to air and air pollution, where the number of stations for air pollution measurement has significantly increased. However, the greatest activity still occurs in large cities and the question of the absence or small number of ground posts for air quality indicators measurement in less populated cities or villages remains open. In this paper it is proposed to use satellite or model open data to fill the gaps in those places where there are no ground measurements. The issue of validation of satellite and model data on the basis of ground measurements for the territory of Ukraine is considered in the work [2].

This article describes the analysis of existing technologies and data in the world, which are used to monitor air quality in cities and countries as a whole, and also proposes an algorithm for creating similar, no less high-quality products for the territory of Ukraine.

The world's largest aggregator of air pollution data is the AQICN resource [3], using the air quality index, the standards of which are calculated by the United States Environmental Protection Agency and visualizes all sensors and information from them using API. It integrates networks of smart cities around the world, as well as national and public air quality monitoring systems. Western Europe, Southeast Asia, North America, and India have the largest sources of information. The estimated number of operating stations of different types is about 13,000 units.

In Western Europe, one of the most popular air quality monitoring initiatives, the most common provider of air pollution data, is the Sensor Community [4], whose developers launched the Luftdaten.info public project in 2015 in Stuttgart, Germany [5]. This project has become a catalyst, including for the development of similar networks of public air quality monitoring in Ukraine.

Another portal used by residents of smart cities of the European Union is Airly [6]. It applies its own technological solutions and provides an opportunity to predict the levels of dust concentrations of fractions $\mathrm{PM}_{2.5}$ and $\mathrm{PM}_{10}$ for 1 day ahead. The service works with more than 300 local authorities, and more than 4,000 devices around the world are integrated into it.

The Swiss commercial project IQAir [7] uses devices to measure air pollution levels both outdoors and indoors, offering appropriate sensors and a mobile application for control and notification. IQAir operates on the world's largest free real-time air quality information platform and attracts a growing number of global citizens, organizations and governments. The IQAir AirVisual platform integrates data collected by governments, companies and individuals around the world.

There are many other global air quality monitoring services that are designed and operated for the territories of the European Union, Great Britain, the United States, etc. Analyzing them, we can conclude that they publish information in the form of levels of concentrations of pollutants. Almost all smart city monitoring systems include Web portals that combine a large amount of environmental and urban data, which is directly or indirectly related to air quality and determines the comfort of the urban environment. The unequivocal advantage and achievement of such systems is the use of a large number of high-density measuring equipment in urban areas. In particular, one of the most common projects, which includes air quality analysis and evaluation of the Sustainable Development Goal 11.6.2 indicator, quality of life, analysis of urban growth and many other important applications, is the SMURBS project [8]. For the most part, almost all air quality monitoring projects involve the Copernicus Atmosphere Monitoring Service (CAMS) global data.

The CAMS service of air quality monitoring and forecasting completely covers the territory of Ukraine, which is a good sign for national developers of air quality monitoring services. However, these data are still not used properly in Ukraine, as applications for cities can be implemented only with presence of an active network of ground stations, 
which allow to clarify the values of pollution concentrations in urban areas and increase the spatial resolution of global raster products. At the same time, over the last three years, public air quality monitoring initiatives and public networks, such as ECO-City and others, have been developing very rapidly in Ukraine. In the future, such data sources may become alternatives to governmental air quality monitoring networks, which can be obtained using Citizen Science. Thus, using these data Ukrainian cities can already get the same opportunities in the implementation of Copernicus data in air quality monitoring over the cities as well as other European cities. The lack of quality national products for urban planning and monitoring of air quality indicators in cities makes it impossible to assess the impact of cities on the environment and human health and calculate such important indicators for achieving sustainable development goals (SDG) as 11.6.2 "Annual mean levels of fine particulate matter in cities" and 11.3.1 "Ratio of land consumption rate to population growth rate".

The National Research foundation of Ukraine project aimed at creating information technology for air quality monitoring in Ukraine based on satellite and in-situ data and development of Urban Atlas for cities of Ukraine. In the future, this will provide opportunities for qualitatively use of new tools for urban planning. Currently, the impact of cities on the environmental situation quality is very large and the assessment of such impact makes it possible to reduce the negative effects of human activities.

\section{Methods}

The methodology for calculating the Sustainable Development Goal Indicator 11.6.2 is based on the methodology proposed by the UN and used within the SMURBS project [8]. The main goal of which was to collect best practices to promote the concept of "smart city" and use it for as many cities as possible by integrating satellite observations to increase the resilience of the environment and society to urban impact. These European activities brought together a large consortium of experts from around the world, who were divided into three main areas of the project: air quality, urban growth, natural or manmade disasters and their consequences. The countries representing this consortium are Greece, Italy, France, Spain, Germany, Switzerland, Slovenia, the Czech Republic, Romania, Finland, as well as Ukraine, represented by the Space Research Institute of the National Academy of Sciences of Ukraine and the State Space Agency of Ukraine [9], [10].

SMURBS project countries that have monitored and developed air quality monitoring systems for pilot cities have developed 22 technical solutions that are currently at different stages of development, depending on the country, city and data available for the pilot area. Typically, all participants use the same type of input to carry out their research and air quality monitoring projects in pilot cities: data from portable sensor ground stations, satellite data and CAMS model data [11] (or other model data that is local to the pilot territories). The National Observatory of Athens has developed a platform for monitoring indicator 11.6.2 for 800 cities and 37 European countries. Ground data is used as input data, on the basis of which models are extended over a larger area. The most common indicator for assessing sustainable development in terms of air quality is 11.6.2, which is the average annual concentration of PM2.5 in Functional Urban Areas (FUA) and in Global Urban Centers (GUC) in terms of population. It is estimated using advanced modeling through the integration of satellite monitoring data, population estimates, topography and ground-based measurements [12]. FUA therefore consist of a densely inhabited city and a less densely populated commuting zone whose labour market is highly integrated with the city.

There are two main methodologies for calculating indicator 11.6.2 (UN methodology and the methodology developed within the SMURBS project), which are based on different data sets. According to these methodologies, all air quality indicators are calculated within the FUA and GUC. The general calculation formula is the same for the two methodologies and is as follows:

$$
S D G 11.6 .2=\Sigma C_{n}{ }^{*} P_{n} / \Sigma P_{n},
$$


where $C_{n}$ - the estimated average value of $\mathrm{PM}_{2.5}$ for the Functional Urban Areas or Global Urban Centers, a $P_{n}$ - population (calculated for the FUA and GUC). This formula is used for countries with available data from ground-based PM2.5 measurements.

The main input data, as can be seen from formula (1) for the calculation of SGD indicator 11.6.2 are ground stations, which measure the concentration of PM2.5 in FUA and GUC, and statistics on urban populations. The quality and availability of the required data. In particular for Ukraine there is no data, which should be used for air quality monitoring. That is why, in cases where the necessary data is not enough, it is necessary to use alternative ways, in particular to use instead it the corresponding satellite data.

Many developed methodologies within the SMURBS project consider model data of air quality CAMS with low spatial resolution $11 \mathrm{~km}$. In this article, according to the methodology of the SMURBS project SDG 11.6.2 indicators for 2014-2018 years are calculated for Ukraine.

\section{Materials}

The main problem for the development of air quality monitoring technologies for the territory of Ukraine, which would be similar to European ones, is the insufficient number of ground stations to measure air quality indicators in less populated cities (for example, in those cities that are part of a FUA). Therefore, the use of satellite data, their validation on the basis of ground data and the development of a methodology to improve the spatial resolution of satellite data is still the right way for air quality monitoring in all settlements of Ukraine. Further it can be used for active calculation the sustainable development indicator 11.6.2 based on the results.

Given the fact that the Ukrainian authorities and the population need qualitative and reliable information on the impact of cities on air quality, within this work, based on European practices and methodologies, SDG 11.6.2 was received for Ukraine in 7 years from 2014 to 2020, with the ability to compare the obtained values with the open service the SMURBS SDG Indicator 11.6.2 Earth Observation Platform for 2014-2018 years [1].

\subsection{Network of ground stations for air quality measurement}

The first steps to create air monitoring systems in large cities of Ukraine - significantly increased the number of stations for measuring air pollution [13]. However, the greatest activities are still related in large cities. It is very important as they make the largest contribution to air pollution. But the question of the absence or small number of ground posts for air quality measurement indicators in less populated cities or villages remains open. The Figure 1 shows a significant difference in the number of ground air quality measurement stations in Europe and Ukraine [14].

The main providers of air quality data in Ukraine are Eco City, Lun Air and Save Dnipro. The Eco City public monitoring project is developing public monitoring of pollution levels not only of fine dust particles $\mathrm{PM}_{10}$ and $\mathrm{PM}_{2.5}$, but also of toxic pollutants nitrogen dioxide, carbon monoxide, formaldehyde, ammonia, ground-level ozone and radiation. LUN's social initiative uses PM1.0, PM2.5 and PM10 sensors to monitor air quality, and Save Dnipro provides data on the following air parameters: PM2.5, PM10, temperature, relative humidity, and atmospheric pressure. The SaveEcoBot service aggregated data by different providers within single platform [13]. 


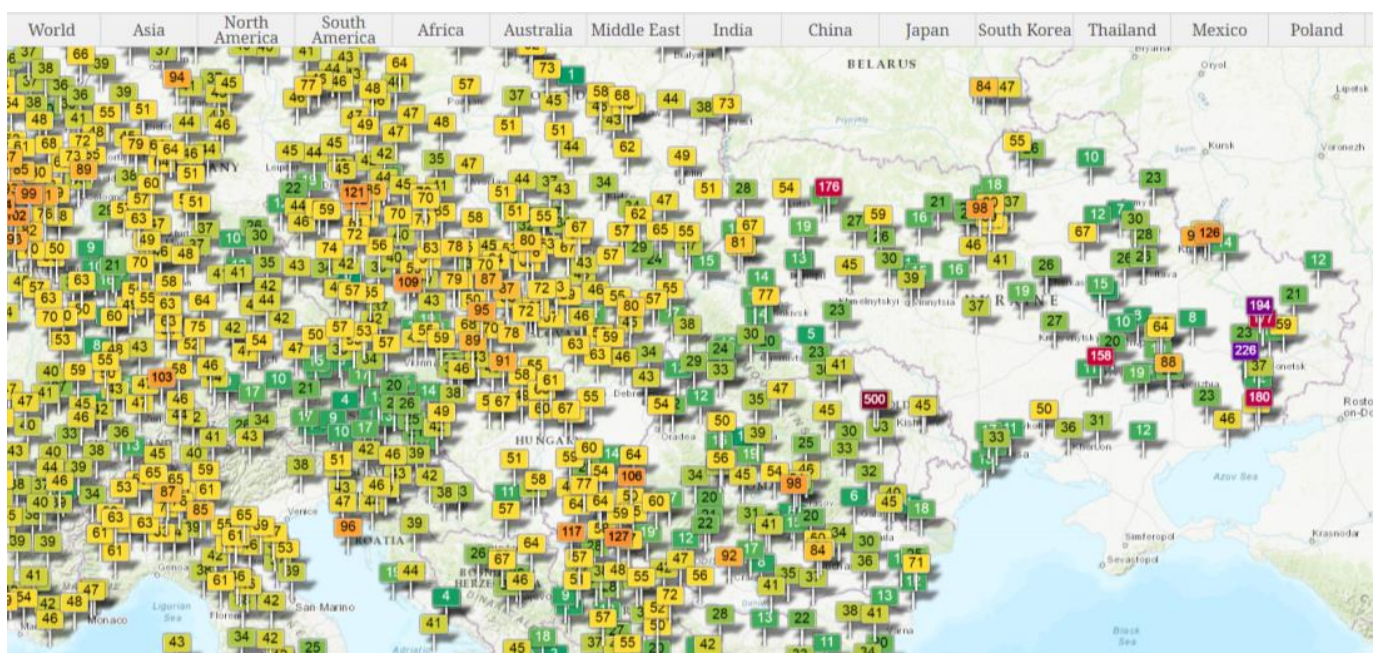

Figure 1. Air Pollution in Europe: Real-time Air Quality Index Visual Map [13]

\subsection{Functional Urban Area}

There is no such standardized concept for the territory of Ukraine as FUA which is used for SDG 11.6.2 indicator calculation in Europe, so to adapt the methodology for assessing the indicator 11.6.2, such zones were created for the main cities of Ukraine. The methodology of the European Commission was chosen as the basis for obtaining FUA for the largest cities of Ukraine [15]. The FUA can be defined in four steps:

1. Identify an urban center: a set of contiguous, high density (1,500 residents per square kilometer) grid cells with a population of 50,000 in the contiguous cells. The global city centers were used, which were created by the Global Human Settlement Layer team in 2015 [16].

2. Identify a city: one or more local units that have at least $50 \%$ of their residents inside an urban center. The local units' boundaries for items 2 and 3 for the territory of Ukraine were used from the Humanitarian Data Exchange (HDX) platform [17].

3. Identify a commuting zone: a set of contiguous local units that have at least $15 \%$ of their employed residents working in the city.

4. A FUA is the combination of the city with its commuting zone.

Thus, we obtained similar to the European FUA territories, within which the SDG indicator was calculated. Figure 2 illustrates the different concepts that are used in the method and that compose a FUA for Kyiv city, notably the urban center, the city, and the commuting zone.

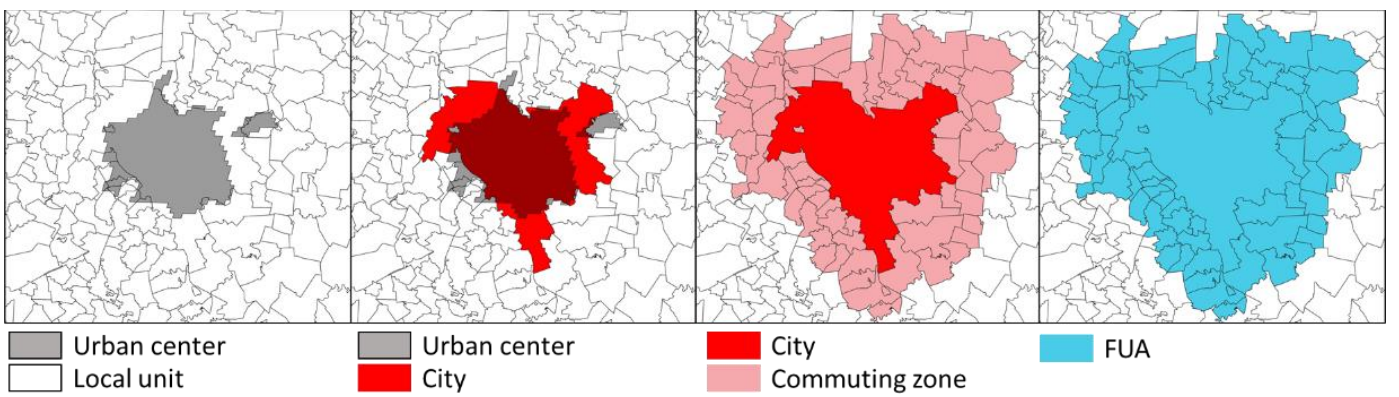

Figure 2. Urban center, city, commuting zone and functional urban area for Kyiv, Ukraine

\subsection{Data from Copernicus Atmosphere Monitoring Service}

Copernicus Atmosphere Monitoring Service (CAMS) has been developed for sharing data and processed information about the Earth's surface, aerosols, ozone and other reactive gases, aiming to support policymakers, business and citizens with enhanced 
atmospheric environmental information. In particular, the service provides daily hourly data $\mathrm{PM}_{2.5}$ and $\mathrm{PM}_{10}$ in the form of close to real-time analysis for Europe and Ukraine with a spatial resolution of $11 \mathrm{~km}$. Also, CAMS provides the average annual PM2.5 model data which were selected as air quality data in this study (Figure 3-a) [11], but it is not available average annual PM2.5 data for 2019-2020 years. To solve our problem, the average annual values for these years were calculated by the authors themselves. The Figure 3-b shows the statistical information of wastes generation in 2018 by regions of Ukraine [18]. Such oblasts as Dnipropetrovska, Donetska and Kirovohradska have the highest statistics on waste generation and, as a consequence, on annual air pollution, as shown by satellite data.
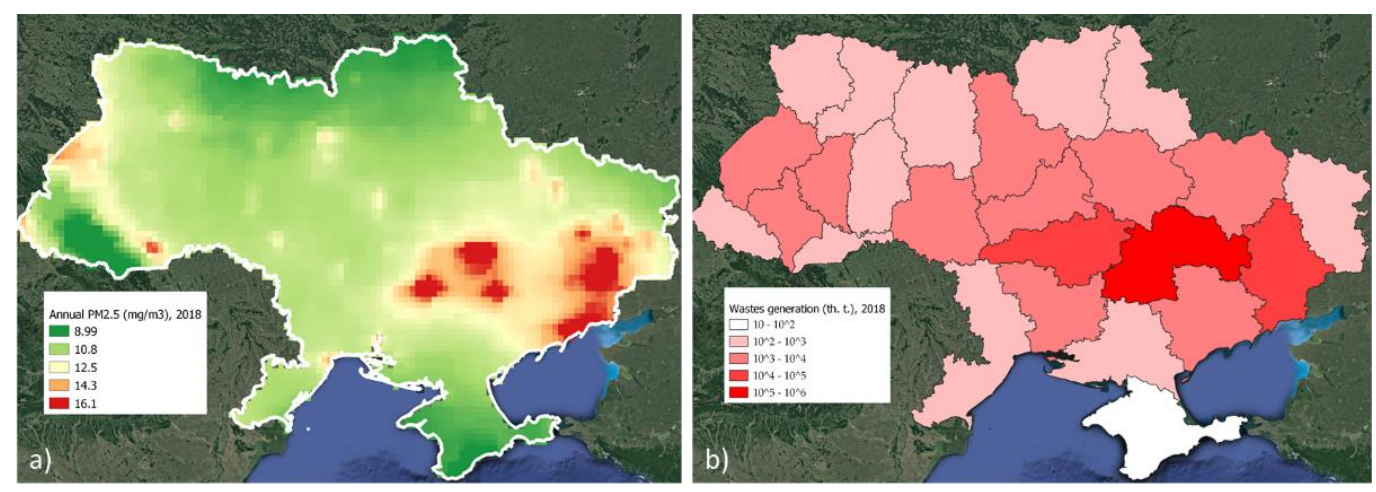

Figure 3. a) annual CAMS PM2.5 values and b) statistical wastes generation in Ukraine, 2018

\subsection{Population data}

For FUA calculation the population data from two sources were used - the Global Human Settlement Layer (GHSL) European Commission (2015) [19] and NASA Population density product (2015 and 2020) [20]. A separate study was conducted on the validation of population data from these sources and it was concluded that Global Human Settlement Layer data have a much higher correlation with statistical information on the population of Ukrainian cities. However, if the calculations are made at the level of the whole country, both products can be used.

\section{Results}

\subsection{CAMS Air quality Data Validation for Ukraine}

The insufficient number of ground-based stations leads to the necessity of search for additional data that allows to analyze air quality across the whole country. In our case, it is satellite data or model data CAMS that provide daily hourly air quality data. The Royal Netherlands Meteorological Institute (KNMI) validates different algorithms of CAMS data modelling for different parts of Europe on the basis of ground stations every day and the root mean square error $\mathrm{PM}_{2.5}$ value in general does not exceed $10 \mathrm{mg} / \mathrm{m}^{3}$ [21]. Unfortunately, such validation is not performed for the territory of Ukraine. Within our investigations CAMS data was validated on the example of the city of Kyiv.

The Figure 4 shows a comparison of daily data from all ground stations for 2019-2020 (the values are in $\left.\mathrm{mg} / \mathrm{m}^{3}\right)$. The R-squared ratio is not very high $(0.36-0.38)$, but is stable for both years. The correlation coefficient shows the best values $(0.5-0.6)$, which allows us to conclude that CAMS data can be used for Kyiv as reliable source of data in analytical tasks. Excluding from the survey those stations (Figure $4-\mathrm{b}$ ) that are statistically outliers (their values are very different from neighboring stations), all statistics was significantly improved for both years (in 2019 the R-squared value has increased from 0.38 to 0.48 , the correlation values has increased from 0.6 to 0.61 , and RMSE value has decreased from $10.7 \mathrm{mg} / \mathrm{m}^{3}$ to $10.1 \mathrm{mg} / \mathrm{m}^{3}$; in 2020 the R-squared value has increased from 0.36 to 0.38 , 
the correlation values has increased from 0.5 to 0.54 , and RMSE value has decreased from $10.5 \mathrm{mg} / \mathrm{m}^{3}$ to $\left.9.7 \mathrm{mg} / \mathrm{m}^{3}\right)$.
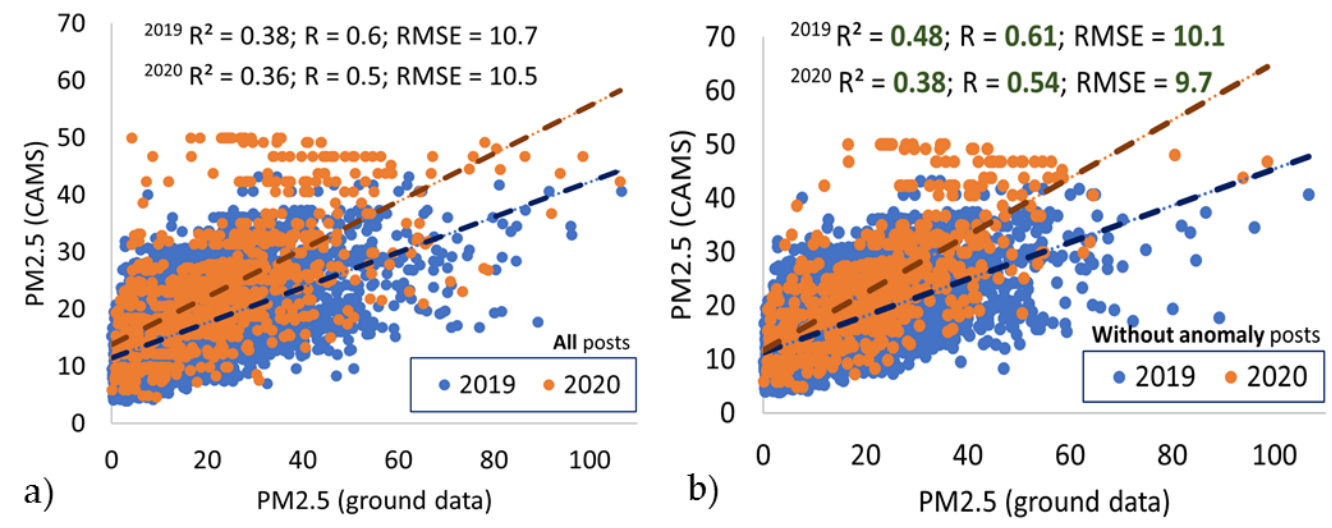

Figure 4. Comparison of daily ground data and CAMS data for 2019 (blue) and 2020 (orange)

Also, from the dependence graph it is seen that the value of PM2.5 from ground stations mostly exceeds the data from CAMS. There is a logical explanation for this - it is a spatial resolution of CAMS data. It does not allow to increase the variability of the values of the contaminant and thus increase the accuracy of CAMS products. A great advantage of satellite and model data for air quality monitoring is the continuous coverage of the study area with data, which cannot be guaranteed in the presence of ground stations only. As a conclusion we can say that CAMS data are reliable global data that can be used in scientific and practical research for the territory of Ukraine.

\subsection{Population Data GHSL and NASA validation for Ukraine}

In this paper the FUA for Ukraine was defined, but it was not defined for Ukraine previously. Accordingly, the question about availability and accessibility of population data within the obtained FUA arose. This question is important because population data is necessary for calculating the SDG indicator 11.6.2. In this case the global products for all the world come to be aid. Namely, the population data Global Human Settlement Layer (GHSL) and global population data from NASA. Accordingly, the first question before using this data for the territory of Ukraine is the question of their verification. To validate GHSL and NASA population data, official population statistics for 2013-2020 were used for the 20 largest cities in Ukraine [22]. Separate validation was conducted in the districts of Kyiv, for which statistical information on the population is available for 2007-2020 [23].

Pearson's correlation coefficient was calculated to verify the relationship between satellite population data and statistics (Table 1, Figure 5). The Global Human Settlement Layer data correlation coefficient for Kyiv districts is close to 0.77 . This means that there is a high direct linear relationship between GHSL data and statistics. NASA data for the districts of Kyiv show a correlation coefficient close to 0.52 , which is characteristic of the direct linear dependence of the average intensity.

Table 1. Pearson's correlation coefficient for different population data providers

\begin{tabular}{ccccc}
\hline Population data provider & \multicolumn{2}{c}{ 20 largest cities } & \multicolumn{2}{c}{ districts of Kyiv } \\
\hline & $\mathbf{2 0 1 5}$ & $\mathbf{2 0 2 0}$ & $\mathbf{2 0 1 5}$ & $\mathbf{2 0 2 0}$ \\
\hline GHSL & 0,995 & N/A & 0,776 & N/A \\
\hline NASA & 0,963 & 0,963 & 0,529 & 0,523 \\
\hline
\end{tabular}

During the analysis, the absolute and relative deviations of GHSL and NASA data from statistical data were calculated. The maximum relative error according to GHSL is about $33 \%$ in the city of Kherson, the minimum error is less than $1 \%$ in the city of Nikolaev. 
In the main part of the cities - the error does not exceed 10\%. At the level of Kyiv districts, the relative deviation mostly not more then $2-10 \%$. Deviation of more than $10 \%$ is observed in Desnyansky and Obolonsky districts. A particularly large deviation (about 50\%) was recorded in Holosiivskyi district.
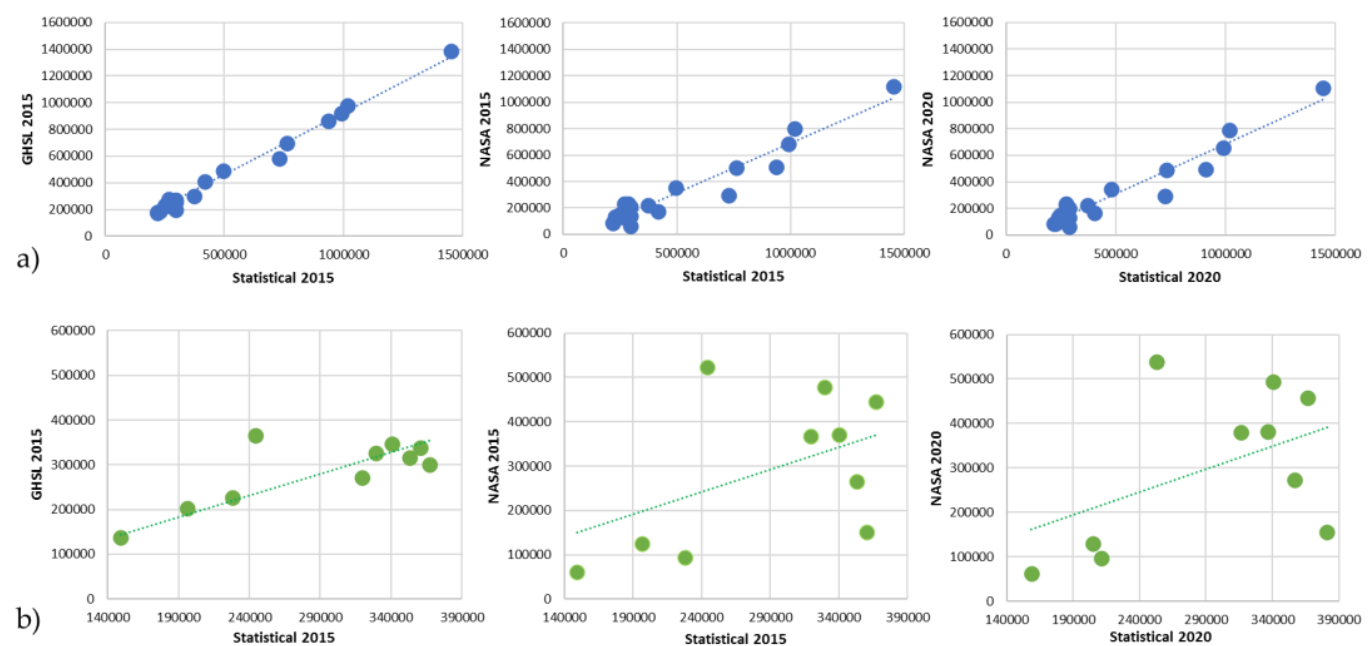

Figure 5. Validation of satellite population data for the largest cities of Ukraine (a) and districts of Kyiv (b)

According to NASA data, the situation is worse, due to the lower spatial resolution of the product. The largest relative error is recorded in the city of Kherson and is about $80 \%$. For other cities, the error exceeds $40 \%$. At the level of districts of the city of Kyiv - a deviation of about 50\%. In Holosiivskyi district, deviations reach even more than 100\%. However, when estimating data not separately by district, but for the whole city, the deviation rates have decreased significantly, in some years not even reaching $7 \%$ for NASA data.

According to the analysis it can be concluded that there is a clear direct linear relationship between GHSL and NASA product data and population statistics and they can be used in studies to determine the SDG indicator 11.6.2 for Ukraine.

\subsection{SDG indicator 11.6.2}

In Figure 6 shows the obtained values of indicator 11.6.2 for Ukraine using different data on the population by FUA and GUC. As follow from the Figure 6, in 2017 there was a significant decline in the indicator responsible for improving air quality in the country as a whole. It can also be noted that the chart shows that indicator 11.6.2 does not change much at the level of the whole country depending on the provider of information on population. This once again confirms the possibility of using global population data to calculate this SDG indicator.

From a comparative analysis of all European countries, which also gave their values to the indicator 11.6.2, we can conclude that in 2017 all countries had better air quality than in all other years. Figure 7 and Figure 8 show the results of the evaluation of indicators 11.6.2 for Ukraine for last 5 years in comparison with European countries (for 2019 and 2020 years there are not available data for SDG indicator for Europe), which calculate this indicator centrally (for FUA and GUC). The Figure 9 demonstrates the obtained indicators of 11.6.2 at the Ukraine level in comparison with European countries in 2018.

It should be mentioned that air quality monitoring product based exclusively on open data sources. 


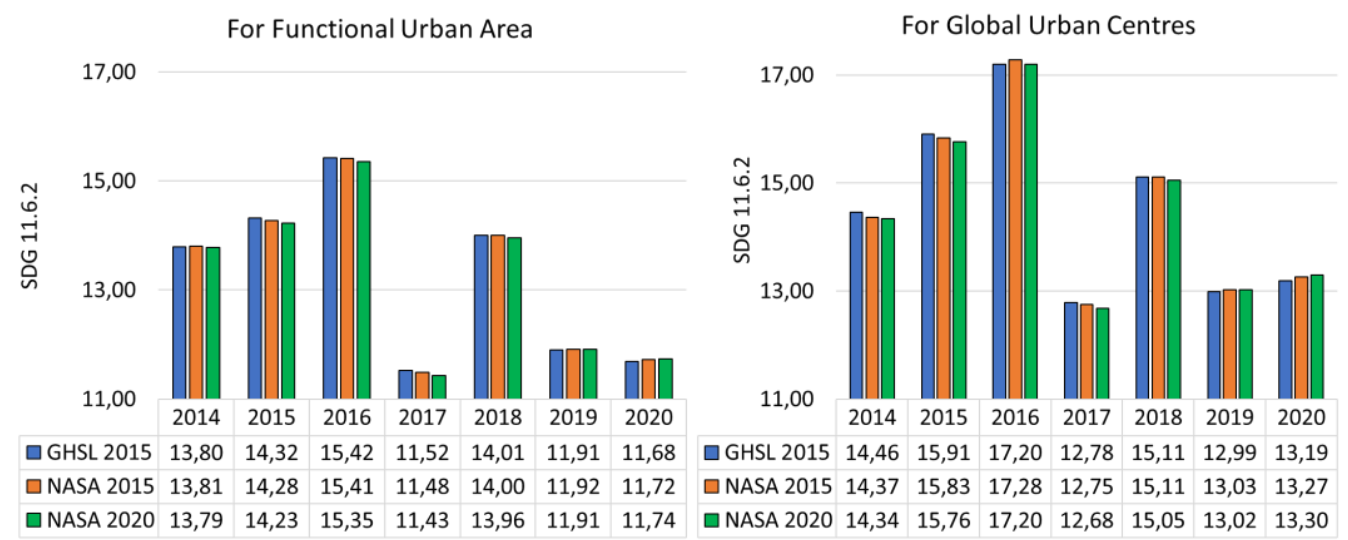

Figure 6. SDG 11.6.2 for Ukraine from 2014 to 2020

Land cover maps have great potential for the analysis of urban areas, as they provide a reliable set of data that can be used for planning and evaluation of various indicators of sustainable development, namely the indicator of achieving the goal of sustainable development 11.6.2 and others.

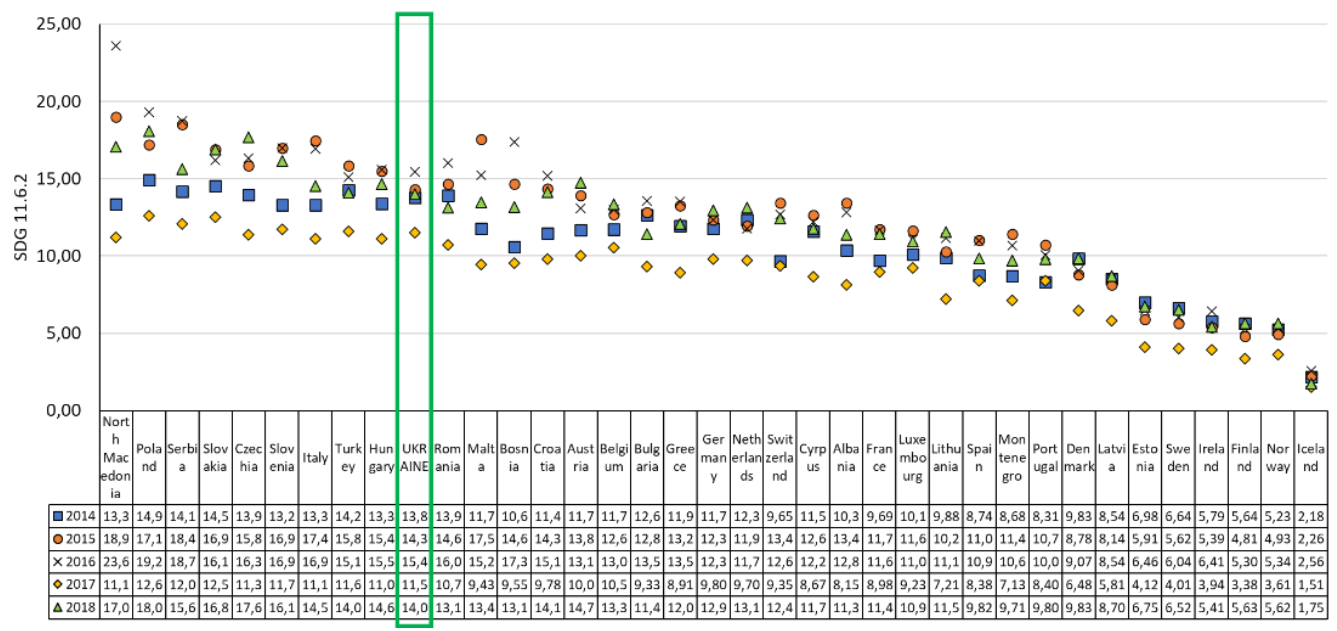

Figure 7. Comparison of the calculated indicator 11.6.2 for Ukraine with the corresponding values for European countries for Functional Urban Areas from 2014 to 2018

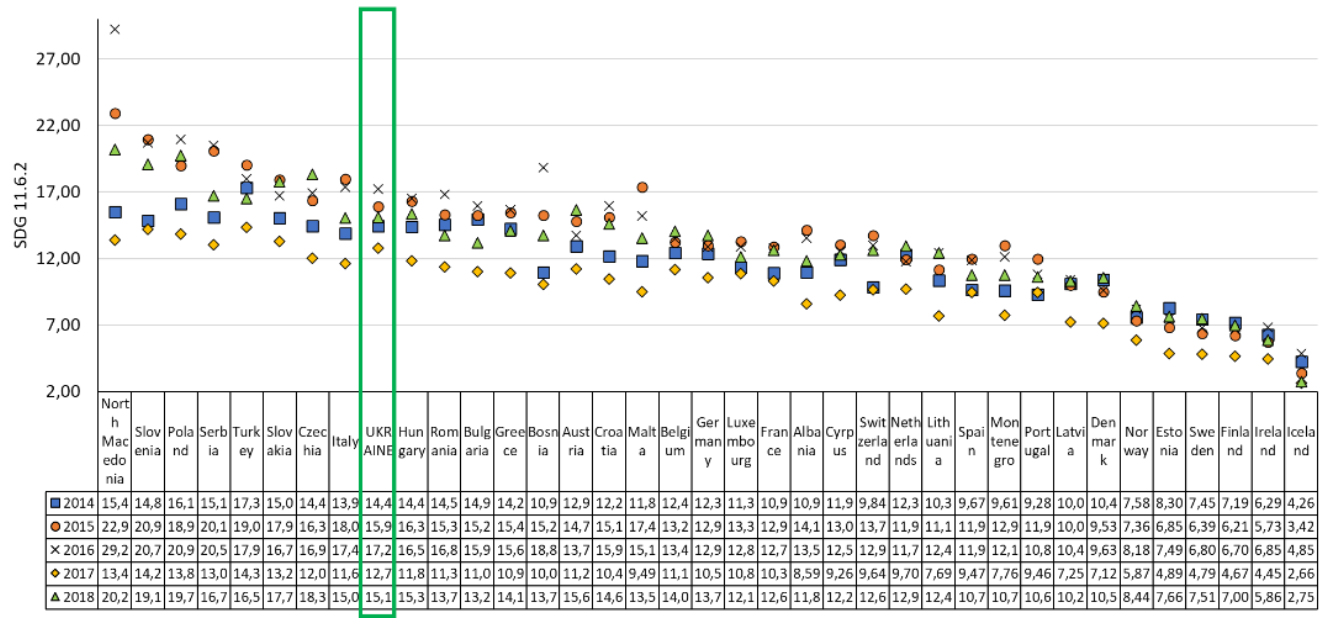

Figure 8. Comparison of the calculated indicator 11.6.2 for Ukraine with the corresponding values for European countries for Global Urban Centers from 2014 to 2018 


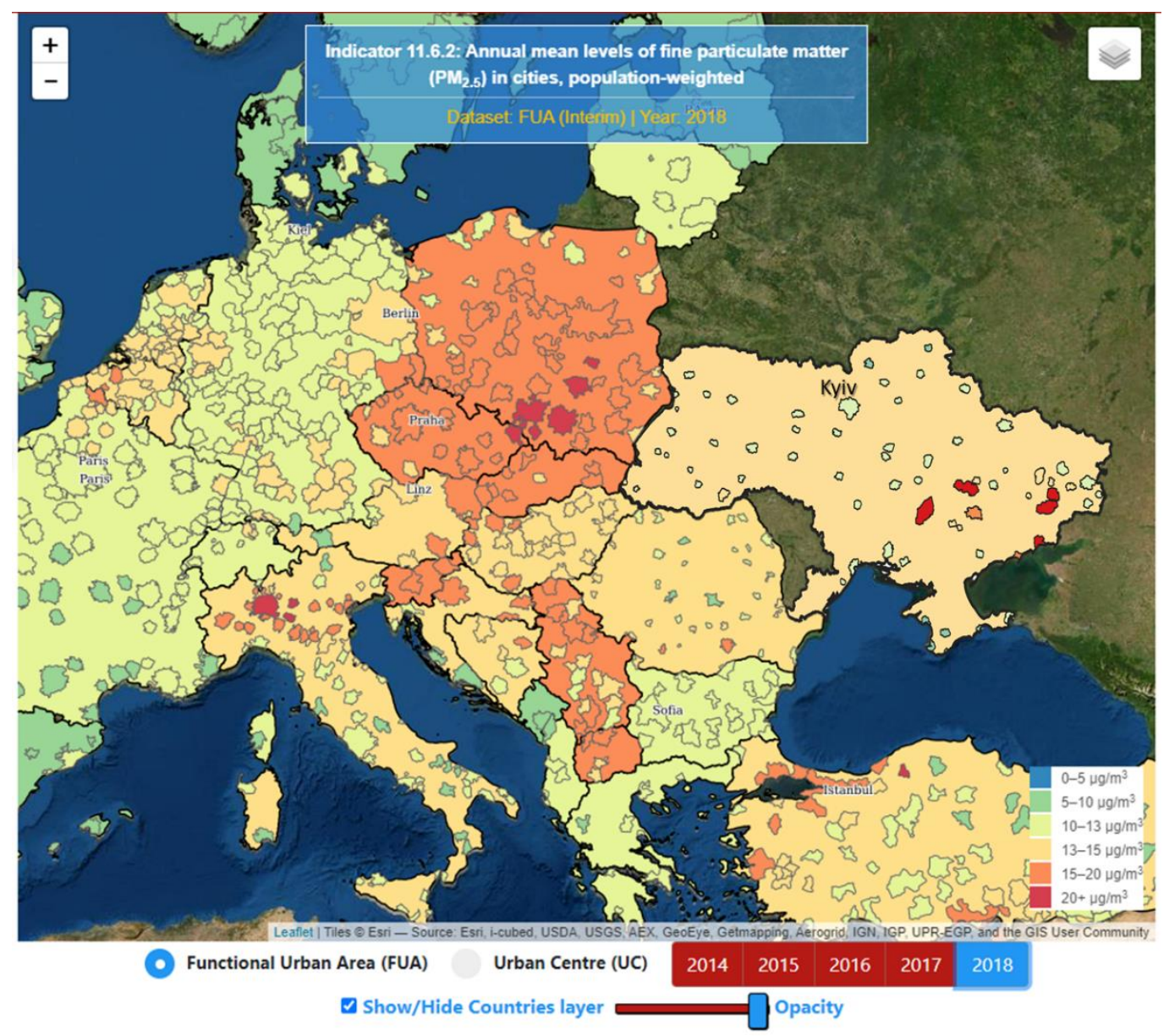

Figure 9. Comparison of the calculated indicator 11.6.2 for Ukraine with the corresponding values for European countries for Functional Urban Areas and Global Urban Centers from 2014 to 2018

\section{Discussion}

According to the obtained results, it is safe to say that cities have the greatest impact on air quality compared to suburban areas. This is shown in the Figure 10 where for European countries and for Ukraine the value of SDG 11.6.2 indicator for FUA is lower than for the GUC. As a further step in the analysis, the authors propose to use the land cover maps, which received their own algorithm for deep learning to classify the time series of satellite data [24, 25], within the FUA. It will help to determine the contribution of cities and other types of land cover to air quality indicator assessment.

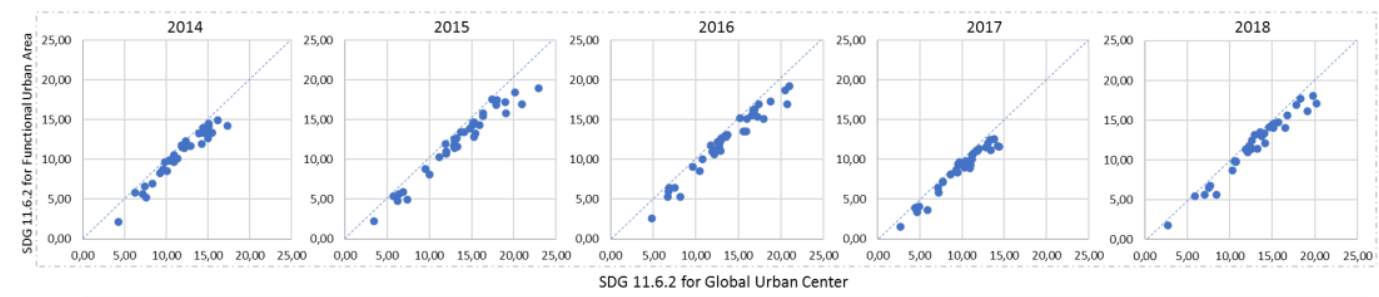

Figure 10. The SDG indicator 11.6.2 for Functional Urban Area and for Global Urban Center comparison for different countries

\section{Conclusions}

The considered air quality monitoring methodologies are just beginning to be adapted and used for the territory of Ukraine, in particular for Kyiv. The use of open CAMS air quality model data is stable, but requires increased spatial resolution because 
this product is too rough for cities. In addition, the ground-based monitoring system using air quality sensors is only beginning to grow in large cities, but has not yet increased in other settlements and villages. This require the development of technology that will allow the use of ground data for those cities where they exist, and to build model values of air pollution based on satellite data in those cities where ground data is insufficient. Of course, a pre-important step is the validation of satellite data on the base of ground data to understand the quality and accuracy of data source.

To understand the meaning of the developed product in terms of air quality, it is compared with similar indicators for European cities. Unfortunately, for Ukraine there is no modern database with the number of populations in cities, which is an integral part of the assessment of the indicator of the sustainable development goal 11.6.2. Therefore, the global products of the Copernicus GHSL program and NASA are used, as in most EU countries. Also, in addition to only the PM2.5 data used in the UN and SMURBS methodologies for the assessment of indicator 11.6.2, in the future all available data on air pollution (both ground and satellite) will be used.

Author Contributions: Conceptualization and methodology, A.S.; data curation, H.Y., B.Y., validation, B.Y.; writing - original draft preparation, H.Y.; writing - review and editing, A.S., N.K.; supervision, A.S., N.K. All authors have read and agreed to the published version of the manuscript.

Funding: This research was funded by National Research foundation of Ukraine within the project 2020.02/0284 «Geospatial models and information technologies of satellite monitoring of smart city problems».

Acknowledgments: The research and the materials described in this paper are the progress stage of the project 2020.02/0284 «Geospatial models and information technologies of satellite monitoring of smart city problems», won the competition "Leading and Young Scientists Research Support" by (NRFU).

Conflicts of Interest: The authors declare no conflict of interest.

\section{References}

1. The SMURBS SDG Indicator 11.6.2 Earth Observation Platform. Available online: http://apcg.meteo.noa.gr/sdg1162/ (accessed on 08 April 2021).

2. Shelestov, A.; Yailymova, H.; Yailymov, B.; Samoilenko, O.; Volynskii, M.; Shumilo, L. Ground Based Validation of Copernicus Atmosphere Monitoring Service Data for Kyiv. IEEE EUROCON 2021 - 19th International Conference on Smart Technologies, 2021, pp. 88-91. DOI: 10.1109/EUROCON52738.2021.9535629.

3. AQICN. Available online: https://aqicn.org/ (accessed on 08 April 2021).

4. Sensor Community. Available online: https://sensor.community/ (accessed on 08 April 2021).

5. Luftdaten monitoring system. Available online: https://luftdaten.info/ (accessed on 08 April 2021).

6. Airly. Available online: https://airly.eu/ (accessed on 08 April 2021).

7. IQAIR. Available online: https://www.iqair.com/ (accessed on 08 April 2021).

8. SMURBS. Available online: https://smurbs.eu/the-project/ (accessed on 08 April 2021).

9. Shelestov, A.; Kolotii, A.; Borisova, T.; Shumilo, L.; et all. Essential variables for air quality estimation. International Journal of Digital Earth 2019, 13:2, 278-298, DOI: 10.1080/17538947.2019.1620881.

10. Shelestov, A.; Kolotii, A.; Lavreniuk, M.; Yailymov, B.; Shumilo, L.; Korsunska Y. Smart City Services for Kiev City Within ERAPLANET SMURBS Project. In 2019 IEEE, Proceedings of the 39th International Conference on Electronics and Nanotechnology, Kyiv, Ukraine, April 16-18, 2019, 784-788, DOI: 10.1109/ELNANO.2019.8783424.

11. Copernicus Atmospheric Monitoring Service. Available online: https://www.regional.atmosphere.copernicus.eu/ (accessed on 08 April 2021).

12. Report Ambient Air Pollution: A global assessment of exposure and burden of disease. World Health Organization, 2016, Geneva. Available online: https://www.who.int/phe/publications/air-pollution-global-assessment/en/ (accessed on 08 April 2021).

13. Air pollution in Ukraine online. Available online: https://www.saveecobot.com/ (accessed on 08 April 2021).

14. Air Pollution in Europe: Real-time Air Quality Index Visual Map. Available online: https://aqicn.org/map/europe/ (accessed on 08 April 2021).

15. Dijkstra L., Poelman H., Veneri P. The EU-OECD definition of a functional urban area. - 2019. DOI: 10.1787/d58cb34d-en.

16. Global Urban Centers. Available online: https://ghsl.jrc.ec.europa.eu/download.php?ds=smod (accessed on 08 April 2021). 
17. The Humanitarian Data Exchange - Ukraine - Subnational Administrative Divisions. Available online: https://data.humdata.org/dataset/ukraine-administrative-boundaries-as-of-q2-2017 (accessed on 08 April 2021).

18. Wastes generation in 2018, by region. Available online: http://www.ukrstat.gov.ua/operativ/operativ2018/ns/uv/uv_2018_u.htm (accessed on 08 April 2021).

19. Global Human Settlement Layer. Available online: https://ghsl.jrc.ec.europa.eu/ (accessed on 08 April 2021).

20. NASA Population density. Available online: https://neo.sci.gsfc.nasa.gov/view.php?datasetId=SEDAC_POP (accessed on 08 April 2021).

21. Validation report of the CAMS near-real time global atmospheric composition service. Available online: https://atmosphere.copernicus.eu/sites/default/files/2021-01/23_CAMS84_2018SC2_D1.1.1_JJA2020.pdf (accessed on 08 April 2021).

22. The current population of Ukraine. Available online: https://ukrstat.org/uk/druk/publicat/Arhiv_u/13/Arch_nnas_zb.htm (accessed on 08 April 2021).

23. Population for districts of Kyiv. Available online: http://www.kiev.ukrstat.gov.ua/p.php3?c=1123\%26lang=1 (accessed on 08 April 2021).

24. Shelestov, A.; Lavreniuk, M.; Vasiliev, V.; Shumilo, L.; Kolotii, A.; Yailymov, B.; Kussul, N.; Yailymova, H. Cloud Approach to Automated Crop Classification Using Sentinel-1 Imagery. IEEE Transactions on Big Data 2019, 6:3, 572-582, DOI: 10.1109/TBDATA.2019.2940237

25. Kussul, N.; Lavreniuk, M.; Skakun, S.; Shelestov, A. Deep learning classification of land cover and crop types using remote sensing data. IEEE Geoscience and Remote Sensing Letters 2017, 14:5, 778-782, DOI: 10.1109/LGRS.2017.2681128 